\title{
The transcriptional STAT3 is a potential target, whereas transcriptional STAT5A/5B/6 are new biomarkers for prognosis in human breast carcinoma
}

\author{
Hua-Tao Wu${ }^{1}$, Jing Liu, ${ }^{1,2}$, Guan-Wu Li ${ }^{3}$, Jia-Xin Shen ${ }^{4}$, Yi-Teng Huang ${ }^{5}$ \\ ${ }^{1}$ Department of General Surgery, The First Affiliated Hospital of Shantou University Medical College, Shantou, PR China \\ ${ }^{2}$ Chang Jiang Scholar's Laboratory, Guangdong Provincial Key Laboratory for Diagnosis and Treatment of Breast Cancer, \\ Shantou University Medical College, Shantou, PR China \\ ${ }^{3}$ Open Laboratory for Tumor Molecular Biology, Department of Biochemistry, The Key Lab of Molecular Biology for High Cancer \\ Incidence Coastal Chaoshan Area, Shantou University Medical College, Shantou, PR China \\ ${ }^{4}$ Department of Hematology, The First Affiliated Hospital of Shantou University Medical College, Shantou, PR China \\ ${ }^{5}$ Health Care Center, The First Affiliated Hospital of Shantou University Medical College, Shantou, PR China \\ Correspondence to: Hua-Tao Wu, email: htwu@stu.edu.cn \\ Jing Liu, email: jliu12@stu.edu.cn
}

Keywords: STAT, breast carcinoma, prognosis, Kaplan-Meier plot, transcription

Received: December 08, $2016 \quad$ Accepted: March 21, $2017 \quad$ Published: March 31, 2017

Copyright: Wu et al. This is an open-access article distributed under the terms of the Creative Commons Attribution License (CC-BY), which permits unrestricted use, distribution, and reproduction in any medium, provided the original author and source are credited.

\section{ABSTRACT}

Signal Transducer and Activators of Transcription (STAT) is a set of transcription factors, involved in diverse cellular functions. Evidences from cell lines, mouse models and human tissues implicate these transcription factors in the oncogenesis of breast cancer. However, the diverse expression patterns and prognostic values of 7 STATs remain to be elucidated. In the current study, we mined the transcriptional and survival data of STATs in patients with breast carcinoma (BC) through ONCOMINE, bc-GenExMiner, Kaplan-Meier Plotter and cBioPortal. It was found that STAT1/2 were up-regulated, whereas STAT3/4/5A/5B were down-regulated in BC patients compared with the normal tissues. The expressions of STAT5A/5B/6 were correlated with decreased levels of histological differentiation. In survival analyses through the Kaplan-Meier plotter database, high transcription levels of STAT2/4/5A/5B/6 were associated with better relapse-free survival (RFS) in all BC patients. Conversely, high STAT3 predicted shorter RFS in BC patients, suggesting that STAT3 is potential targets for precision therapy to BC patients. These data also provided STAT5A/5B/6 as new biomarker for BC prognosis.

\section{INTRODUCTION}

Signal Transducer and Activators of Transcription (STAT) is a set of latent cytoplasmic transcription factors that are downstream factors of cytokines and enable the cell to specifically respond to changing environment. Since their identification [1], the STAT family have been recognized as critical integrators of cytokines, hormones and growth factor receptor signaling to regulate cell growth, differentiation, transformation, apoptosis, and survival. The mammary gland is the unique organ that undergoes large-scale proliferation and invasion of the fatpad during puberty, and the STAT factors are reported to be involved in every stage of mammary gland development, as well as breast tumorigenesis [2].
Breast carcinoma (BC), one of the leading cause of cancer-related deaths among women in United States, is supposed to be a multifaceted disease of distinct biological subtypes with diverse clinical, pathological and molecular features [3]. The molecular classification of breast cancer, based on the expression of estrogen receptor/progesterone receptor $(\mathrm{ER} / \mathrm{PR})$ and epidermal growth factor receptor 2 (HER2), provided different prognostic/predictive implications and therapeutic information [4]. The steroid hormone receptors are the upstream of STAT signaling pathway and regulate STAT-dependent transcription, interestingly, STATs are capable to modulate steroid hormone-mediated transcription [5].

So far, seven STAT proteins have been identified in mammalian cells, numbered according to the order of 
discovery (STAT1, STAT2, STAT3, STAT4, STAT5A, STAT5B and STAT6) [2]. Among them, STAT3 and STAT5 is indicated as the oncogene in the process of pathogenesis of $\mathrm{BC}$, based on evidences from breast cancer cell lines, animal models, and primary human tissues [6]. Marrero et al. reported that in response to angiotensin II, STAT 1/2 can be rapidly tyrosine-phosphorylated, which is an important process in JAK/STAT pathway [7]. The post-translational modification may change the different conformations of STAT. For example, depending on the signal transduction pathway responsible, different effects of Prl and Src on STAT5B tyrosine phosphorylation induced the conformational differences of STAT5B, resulting selective biological responses [8]. It was reported that STAT5B signaling might promote the proliferation of ER-positive tumors [9]. On the other hand, Muller et al. screened and identified new loci required for JAK/STAT signaling pathway, providing molecular insights for human cancer [10]. However, the underlining mechanism which STAT is activated or depressed by different hormones and distinct STAT factors' functions in BC has not been well elucidated.

The development of microarray technology revolutionized RNA and DNA research which has become an essential component of biology and biomedical research [11]. Based on the thousands of gene expression or copy number variation analysis published online, in this study, we performed a deep analysis of the expression and mutation of different STAT factors in BC patients, to determine their expression patterns, the potential functions and distinct prognostic values in $\mathrm{BC}$.

\section{RESULTS}

\section{The transcription levels of STATs in patients with breast cancer}

As mentioned before, 7 STAT factors were identified in mammalian cells. In Figure 1, we compared the transcription levels of STATs in cancers with that in normal samples, using ONCOMINE databases, and found that the mRNA expressions of STAT1 were significantly up-regulated in BC patients in 23 datasets. In Curtis's dataset [12], overexpression of STAT1 was found in all types of $\mathrm{BC}$ compared with normal samples, medullary $\mathrm{BC}$ with fold change $=6.511$, invasive ductal $\mathrm{BC}$ with fold change $=3.025$, invasive lobular $\mathrm{BC}$ with fold change $=$ 2.223 and ductal breast carcinoma in Situ with fold change $=2.673$ (Table 1). Another increased mRNA expression factor was STAT2 with fold change $=2.196$ in patients with invasive $\mathrm{BC}$, compared with normal breast tissues, reported by Cluck [13]

The mRNA expressions of STAT3, STAT4, STAT5A and STAT5B were found down-regulated in patients with $\mathrm{BC}$. The transcription levels of STAT3 in ductal BC and invasive breast carcinoma stroma were lower than that in breast tissues (Fold changes were -2.176 and -11.013, respectively) $[14,15]$. Only in TCGA breast statistics, we found that the mRNA expression of STAT4 in mucinous $\mathrm{BC}$ was decreased with fold change $=-2.816$ and $p$ $=0.005$. For STAT5A and STAT5B, the similar trend was found in Curtis and Zhao's datasets $[12,16]$. Both STAT5A and STAT5B were significantly down-regulated in invasive ductal $\mathrm{BC}$, with fold change $=-2.134$ and -2.102 respectively (Table 1). However, no significant difference was found between the transcription levels of STAT6 in breast cancer tissues and normal samples.

\section{The relationship between mRNA levels of STATs and clinicopathological parameters of $\mathrm{BC}$ patients}

In bc-GenExMiner, the Welch's test was performed to compare the mRNA expression of STAT factors between groups of patients, according to different clinicopathological parameters. For age criterion (Table 2), there was no significant difference between $\leq 51$ y and $>51$ y groups, except for STAT4 with down-expression in older group. BC patients with positive nodal status showed higher STAT2 mRNA and lower STAT3/5A mRNA than negative-nodal patients.

ER and PR status were found to be negatively correlated with STAT1/4 expression and positively correlated with STAT5B/6 expression. For STAT3/5A, high mRNA levels were found in BC patients with PR $(+)$. In BC patients with HER2 over-expression, the transcription levels of STAT1/2/4 were significantly increased compared with HER2-negative groups. Triplenegative breast cancer (TNBC) is a special type of $\mathrm{BC}$, with ER (-), PR (-) and HER2 (-). We found that the STAT1/4 mRNA expression was significantly up-regulated in TNBC patients, whereas the STAT5B/6 mRNA expression was significantly down-regulated in TNBC patients (Table 2).

In Scarff Bloom \& Richardson grade status (SBR) criterion (Figure 2), more advanced SBR grade was associated with the higher mRNA level of STAT1 and lower mRNA levels of STAT5A/5B/6. For the STAT2/3/4, although a global significant difference was achieved, all of the groups comparison (SBR1 vs. SBR2, SBR1 vs. SBR3, and SBR2 vs. SBR3) of these factors did not meet the cutoff, $p<0.05$ (Supplementary Table 1).

\section{Increased mRNA expressions of STAT2/4/5A/5B/6 and decreased mRNA expression of STAT3 were associated with better RFS of BC patients}

The Kaplan-Meier curve and log-rank test analyses revealed that STAT2/4/5A/5B/6 mRNA levels and decreased STAT3 mRNA level were significantly associated with RFS $(p<0.05)$ (Figure 3) in all BC patients. The $\mathrm{BC}$ patients with higher mRNA levels of 
STAT2/4/5A/5B/6 factors or lower mRNA level of STAT3 were predicted to have better RFS.

\section{The alterations in STAT factors affected the OS, not DFS in BC patients}

The alterations of STATs occurred in 76 samples out of 963 patients with breast invasive carcinoma (7\%). Almost half of them (36 samples) have two or more alterations (Figure 4C). After analyzed by Kaplan-Meier plot and log-rank test, the alterations in STATs were associated with poorer overall survival (OS) in BC patients (Figure 4A). However, there was no significant difference between disease-free survival (DFS) in BC patients with/ without STAT alterations (Figure 4B).

\section{DISCUSSION}

Recently, Haricharan et al. provided a systematic review of STAT signaling in mammary gland differentiation, cell survival and tumorigenesis [2], indicating the importance of STAT signaling in both mammary gland and breast carcinoma development. STAT proteins, including STAT1/2/3/4/5A/5B/6, were all reported to be expressed in $\mathrm{BC}$ cell lines or $\mathrm{BC}$ tissues. However, the distinct roles of STAT factors in the development and metastasis of breast carcinoma remain to be elucidated. This study analyzed, for the first time, the mRNA expression and prognostic value of different STAT factors in breast carcinoma.

STAT1, first member of this family, is supposed to be a tumor suppressor in breast tumorigenesis. In animal model, STAT $1^{-/}$may promote the spontaneous formation of breast tumors [17], with increasing susceptibility to tumorigensis initiated by ErbB2 [18] and chemical carcinogenesis [19]. However, the mRNA level of STAT1 was significantly up-regulated in breast cancer, and increased in higher SBR grade, which predicted fast-growing, spreading tumors. A DNA microarray analysis identified that RNA interference of CD24, the breast cancer stem cells (BCSC) marker, could increase the expression of STAT1, which enhanced invasiveness

\begin{tabular}{|c|c|c|c|c|c|c|c|c|c|c|c|c|c|c|}
\hline \multirow{2}{*}{\begin{tabular}{|c|} 
Analysis Type by Cancer \\
Bladder Cancer \\
\end{tabular}} & \multicolumn{2}{|c|}{$\begin{array}{c}\text { Cancer } \\
\text { vs. } \\
\text { Normal } \\
\text { STAT1 }\end{array}$} & \multicolumn{2}{|c|}{$\begin{array}{l}\text { Cancer } \\
\text { vs. } \\
\text { Normal } \\
\text { STAT2 }\end{array}$} & \multicolumn{2}{|c|}{$\begin{array}{c}\text { Cancer } \\
\text { vs. } \\
\text { Normal } \\
\text { STAT3 }\end{array}$} & \multicolumn{2}{|c|}{$\begin{array}{l}\text { Cancer } \\
\text { vs. } \\
\text { Normal } \\
\text { STAT4 }\end{array}$} & \multicolumn{2}{|c|}{$\begin{array}{c}\text { Cancer } \\
\text { vs. } \\
\text { Normal } \\
\text { STAT5A }\end{array}$} & \multicolumn{2}{|c|}{$\begin{array}{l}\text { Cancer } \\
\text { vs. } \\
\text { Normal } \\
\text { STAT5B }\end{array}$} & \multicolumn{2}{|c|}{$\begin{array}{c}\text { Cancer } \\
\text { vs. } \\
\text { Normal } \\
\text { STAT6 }\end{array}$} \\
\hline & 2 & & & & & & & 2 & & & 1 & 1 & & \\
\hline Brain and CNS Cancer & 6 & & & & 3 & & & 3 & 1 & & 2 & & 1 & \\
\hline Breast Cancer & 23 & & 1 & & & 2 & & 1 & & 18 & & 10 & & \\
\hline Cervical Cancer & 4 & & & & & & & & & & & & & \\
\hline Colorectal Cancer & 2 & & & 1 & & & & 3 & & & & 1 & & \\
\hline Esophageal Cancer & 3 & & & & & & & 2 & 1 & & & & & \\
\hline Gastric Cancer & 2 & & & & 3 & & & & 1 & & 1 & & & \\
\hline Head and Neck Cancer & 13 & & 3 & & 3 & & & & & & & 1 & & \\
\hline Kidney Cancer & 6 & & 1 & & & 1 & 2 & & & & & 1 & 3 & \\
\hline Leukemia & 3 & 5 & 1 & & & 3 & & 7 & 1 & 3 & & 1 & & 3 \\
\hline Liver Cancer & 5 & & & & & 1 & & & & & & & & \\
\hline Lung Cancer & 7 & 1 & & & & 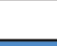 & & 2 & & 4 & & & & 3 \\
\hline Lymphoma & 17 & 2 & 2 & & & 3 & 2 & 7 & 1 & 4 & & 2 & 2 & 1 \\
\hline Melanoma & 2 & & 1 & & 2 & & & & & . & & & 1 & \\
\hline Myeloma & 1 & & & & 1 & & 1 & & & 1 & & & & \\
\hline Other Cancer & 12 & & 5 & & 3 & & & 5 & & 1 & 1 & 1 & 3 & \\
\hline Ovarian Cancer & 4 & & & & & & & & & 1 & & 3 & & 1 \\
\hline Pancreatic Cancer & 5 & & 1 & & & & & & & & & & & \\
\hline Prostate Cancer & & & & & 2 & 1 & & & & & & & 1 & \\
\hline Sarcoma & 1 & & & & & 3 & & 2 & & 5 & & 5 & 1 & 1 \\
\hline \multirow{3}{*}{$\begin{array}{r}\text { Significant Unique Analyses } \\
\text { Total Unique Analyses }\end{array}$} & 117 & 6 & 15 & 1 & 17 & 14 & 5 & 32 & 5 & 36 & 5 & 26 & 12 & 9 \\
\hline & \multicolumn{2}{|c|}{369} & \multicolumn{2}{|c|}{332} & \multicolumn{2}{|c|}{358} & \multicolumn{2}{|c|}{351} & \multicolumn{2}{|c|}{321} & \multicolumn{2}{|c|}{368} & \multicolumn{2}{|c|}{354} \\
\hline & & 1 & 5 & 10 & & 10 & 5 & 1 & & & & & & \\
\hline
\end{tabular}

Figure 1: The transcription levels of STAT factors in different types of cancers. This graphic was generated from $O N C O M I N E$, indicating the numbers of datasets with statistically significant $(p<0.01)$ mRNA over-expression (Red) or down-expression (Blue) of STATs (different types of cancer vs. corresponding normal tissue). Cell color was determined by the best gene rank percentile for the analyses within the cell, and the gene rank was analyzed by percentile of target gene in the top of all genes measured in each research. 
Table 1: The significant changes of STATs expression in transcription level between different types of $\mathrm{BC}$ and breast tissues (ONCOMINE database)

\begin{tabular}{|c|c|c|c|c|c|}
\hline & Types of BC vs. Breast & Fold change & $P$ value & $t$-test & Ref \\
\hline \multicolumn{6}{|l|}{ STAT1 } \\
\hline & Medullary BC & 6.511 & $5.38 \mathrm{E}-15$ & 12.633 & Curtis [17] \\
\hline & Invasive $\mathrm{BC}$ & 3.207 & $1.06 \mathrm{E}-7$ & 7.389 & \\
\hline & Invasive Ductal BC & 3.025 & $4.35 \mathrm{E}-77$ & 28.632 & \\
\hline & Ductal BC & 2.673 & $3.25 \mathrm{E}-4$ & 4.960 & \\
\hline & Invasive Lobular BC & 2.223 & $2.84 \mathrm{E}-29$ & 12.716 & \\
\hline & Invasive Ductal and Invasive Lobular BC & 2.247 & $8.41 \mathrm{E}-20$ & 10.609 & \\
\hline & Total BC & 2.850 & $3.22 \mathrm{E}-4$ & 4.405 & \\
\hline \multicolumn{6}{|l|}{ STAT2 } \\
\hline & Invasive BC & 2.196 & $7.74 \mathrm{e}-4$ & 2.196 & Gluck [18] \\
\hline \multicolumn{6}{|l|}{ STAT3 } \\
\hline & Ductal BC & -2.176 & $1.00 \mathrm{E}-8$ & -7.149 & Richardson [19] \\
\hline & Invasive $\mathrm{BC}$ & -11.013 & $1.21 \mathrm{E}-15$ & -17.246 & Finak [20] \\
\hline \multicolumn{6}{|l|}{ STAT4 } \\
\hline & Mucinous BC & -2.816 & 0.005 & -4.921 & TCGA breast \\
\hline \multicolumn{6}{|l|}{ STAT5A } \\
\hline & Invasive Ductal BC & -2.134 & $7.70 \mathrm{E}-7$ & -7.766 & Zhao [21] \\
\hline \multicolumn{6}{|l|}{ STAT5B } \\
\hline & Invasive Ductal BC & -2.102 & $3.80 \mathrm{E}-4$ & -6.165 & Zhao \\
\hline
\end{tabular}
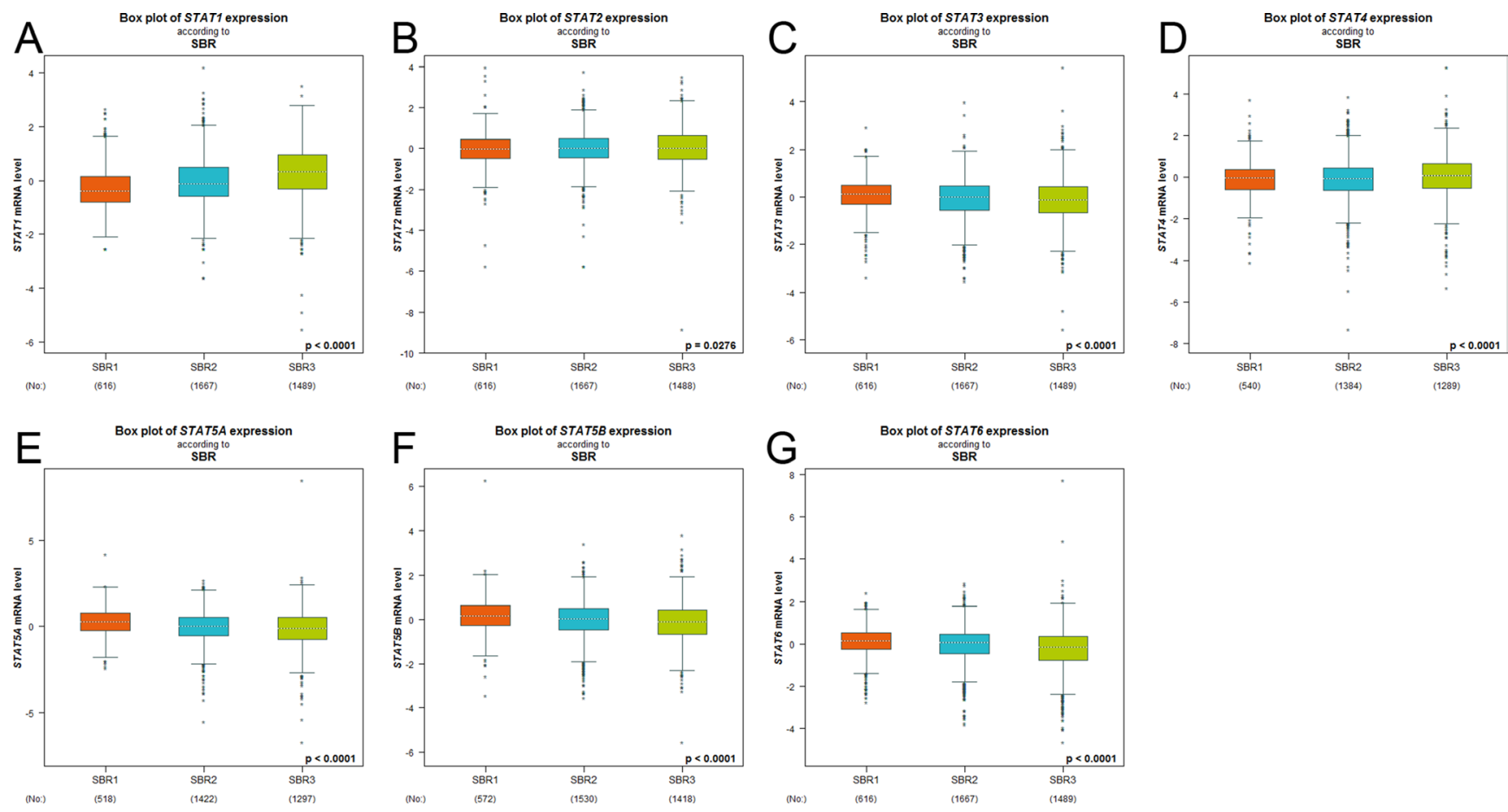

Figure 2: The relationship between mRNA expression of STAT factors and Scarff Bloom \& Richardson grade status (SBR). Global significant different between groups was assessed by Welch's test to generate $p$ value, along with Dunnett-Tukey-Kramer's tests for pairwise comparison when a global significant difference exists $(p<0.05)$. 
Table 2: The relationship between mRNA expression of STATs and clinicopathological parameters of breast carcinoma

\begin{tabular}{|c|c|c|c|c|c|c|c|c|c|c|c|c|c|c|c|}
\hline \multirow{2}{*}{ Variables } & \multicolumn{3}{|c|}{ STAT1 } & \multicolumn{2}{|c|}{ STAT2 } & \multicolumn{2}{|c|}{ STAT3 } & \multicolumn{2}{|c|}{ STAT4 } & \multicolumn{2}{|c|}{ STAT5A } & \multicolumn{2}{|c|}{ STAT5B } & \multicolumn{2}{|c|}{ STAT6 } \\
\hline & No.* & mRNA & $p$ value & mRNA & $p$ value & mRNA & $p$ value & mRNA & $p$ value & mRNA & $p$ value & mRNA & $p$ value & mRNA & $p$ value \\
\hline \multicolumn{16}{|l|}{ Age } \\
\hline$\leq 51$ & 1523 & - & 0.1698 & - & 0.0896 & - & 0.1564 & - & 0.0019 & - & 0.2543 & - & 0.2560 & - & 0.2137 \\
\hline$>51$ & 2331 & - & & - & & - & & $\downarrow$ & & - & & - & & - & \\
\hline \multicolumn{16}{|c|}{ Nodal status } \\
\hline- & 2493 & - & 0.1769 & - & 0.0184 & - & 0.0008 & - & 0.7510 & - & 0.0043 & - & 0.1274 & - & 0.0563 \\
\hline+ & 1814 & - & & $\uparrow$ & & $\downarrow$ & & - & & $\downarrow$ & & - & & - & \\
\hline \multicolumn{16}{|l|}{ ER (IHC) } \\
\hline - & 1617 & - & $<0.0001$ & - & 0.1557 & - & 0.1056 & - & $<0.0001$ & - & 0.4237 & - & $<0.0001$ & - & $<0.0001$ \\
\hline+ & 4169 & $\downarrow$ & & - & & - & & $\downarrow$ & & - & & $\uparrow$ & & $\uparrow$ & \\
\hline \multicolumn{16}{|l|}{ PR (IHC) } \\
\hline- & 1076 & - & $<0.0001$ & - & 0.4143 & - & 0.0022 & - & $<0.0001$ & - & 0.0201 & - & $<0.0001$ & - & $<0.0001$ \\
\hline+ & 1545 & $\downarrow$ & & - & & $\uparrow$ & & $\downarrow$ & & $\uparrow$ & & $\uparrow$ & & $\uparrow$ & \\
\hline \multicolumn{16}{|c|}{ HER2 (IHC) } \\
\hline- & 1598 & - & $<0.0001$ & - & 0.0099 & - & 0.7463 & - & 0.0001 & - & 0.1000 & - & 0.3004 & - & 0.1407 \\
\hline+ & 215 & $\uparrow$ & & $\uparrow$ & & - & & $\uparrow$ & & - & & - & & - & \\
\hline \multicolumn{16}{|c|}{ Triple-negative Status } \\
\hline Not & 4349 & - & $<0.0001$ & - & 0.7214 & - & 0.1016 & - & $<0.0001$ & - & 0.2864 & - & 0.0215 & - & $<0.0001$ \\
\hline TNBC & 419 & $\uparrow$ & & - & & - & & $\uparrow$ & & - & & $\downarrow$ & & $\downarrow$ & \\
\hline
\end{tabular}

*The number of patients was based on the group of STAT1 dataset. The exact number of patients in other group may be a little different.
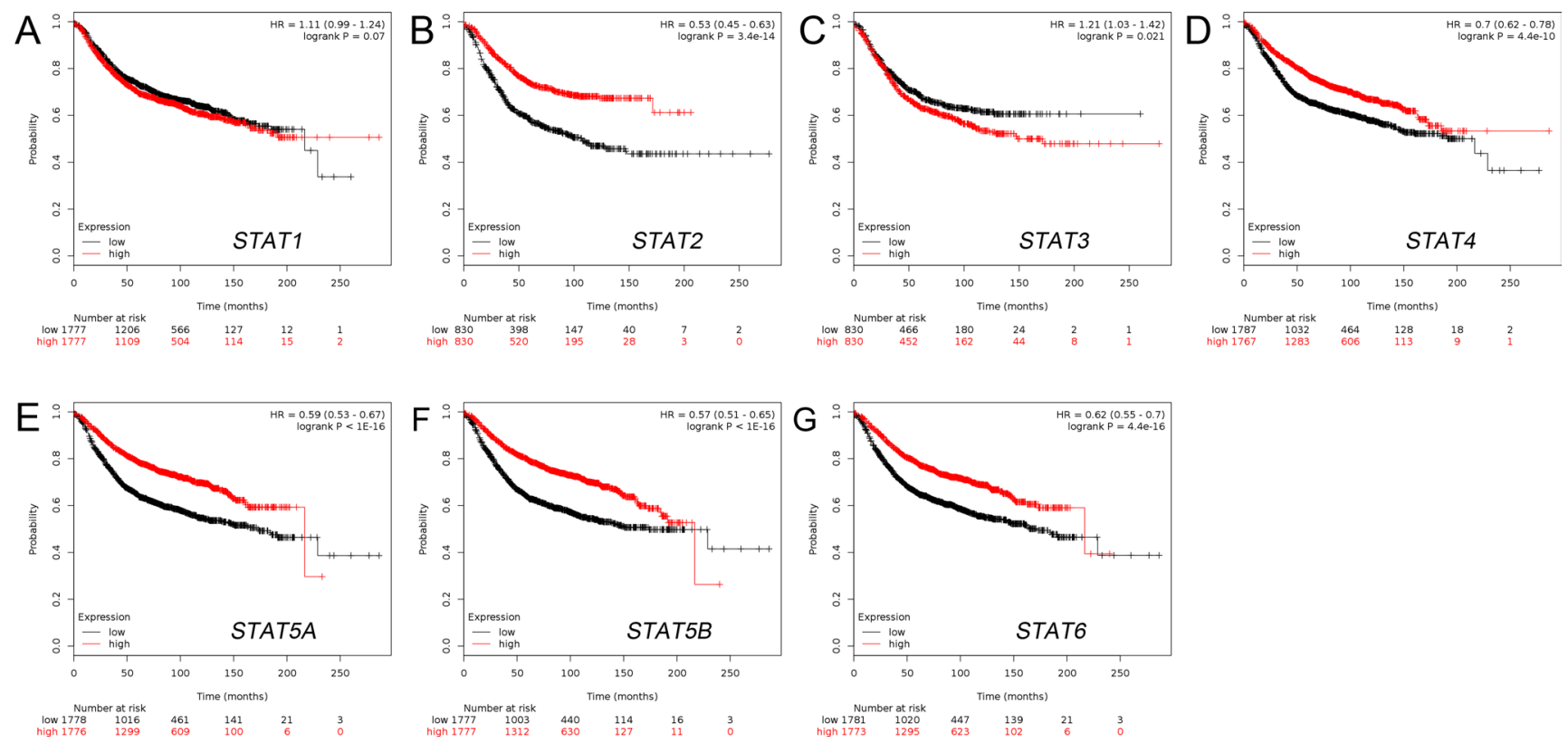

Figure 3: The prognostic value of mRNA level of STAT factors in BC patients (RFS in Kaplan-Meier plotter). (A) STAT1 (200887_s_at). (B) STAT2 (225636_at). (C) STAT3 (225289_at). (D) STAT4 (206118_at). (E) STAT5A (203010_at). (F) STAT5B (212549_at). (G) STAT6 (201331_s_at). 
and superior tumorigenicity [20]. Recently, Jeon et al. pointed that EGFR and HER2 dimerization induced aberrant ACTA2 expression through a JAK2/STAT1 pathway, accelerating the invasiveness and metastasis of breast cancer cells [21]. Magkou et al. demonstrated that menopausal status affected STAT1 functions as a tumor suppressor [22], indicating the crosstalk between STATs and ER signaling pathway with unclear mechanism.

STAT2, forming heteromeric complexes with STAT1, was found in MCF7 cells, an ER+ human BC cell line [23]. In the current study, STAT2 was increased in BC tissues, similar with STAT1. However, the BC patient with higher mRNA levels of STAT2 was predicted with better RFS. On the protein level, Ogony et al. recently reported that overexpression of IFITM1 enhances the aggressive phenotype of TNBC cells in STAT2-dependent manner [24]. As few evidences focused on STAT2, the underlining function of STAT2 needs more researches.

Constitutive STAT3 activation was reported with various human cancers, usually with poor outcome, as a promising target for cancer therapy [25]. Not surprisingly, the transcription level of STAT3 was negatively associated with RFS of BC patients, consistent with the protein level. STAT3 transactivates proliferative genes (cMyc and Cyclin D1), prosurvival genes (Bcl-xl and Survivin) and invasive genes (VEG-f and $K l f-8$ ) [26], resulting in rapidly growing tumors with highly metastastic capacity. In transgenic mice model, STAT3 also establishes an inmuunosuppressive microenvironment during the early stages of breast carcinogenesis to promote tumor develop and metastasis [27]. Zhang et al. recently found that STAT3 could bind promoter region of TXNDC17 and up-regulated its expression, mediating Taxol resistance via enhancing autophagy in human colorectal cancer cells [28], which may be also involved in the mechanism of chemoresistance in BC patients, whereas Bui et al. found that Notch4/ STAT3 signaling induced the epithelial-mesenchymal transition in tamoxifen-resistant human breast cancer, increasing micrometastatic tumor burden [29].

MCF7 cells also expressed STAT4 [23], without specific evidence of STAT4 expression in human BC. We found that STAT4 was down-regulated in BC patients and higher STAT4 expression predicted better RFS. However, considering hormone receptor criterions, STAT4 showed positive correlation with TNBC, a more aggressive type with poor prognosis. Crytotanshinone (CPT) showed potential therapeutic value in animal breast model through enhancing cytotoxic CD4+ T cells by up-regulating JAK2 and STAT4 phosphorylation [30], suggesting that STAT4 may be play opposite function with STAT3 in human cancers.
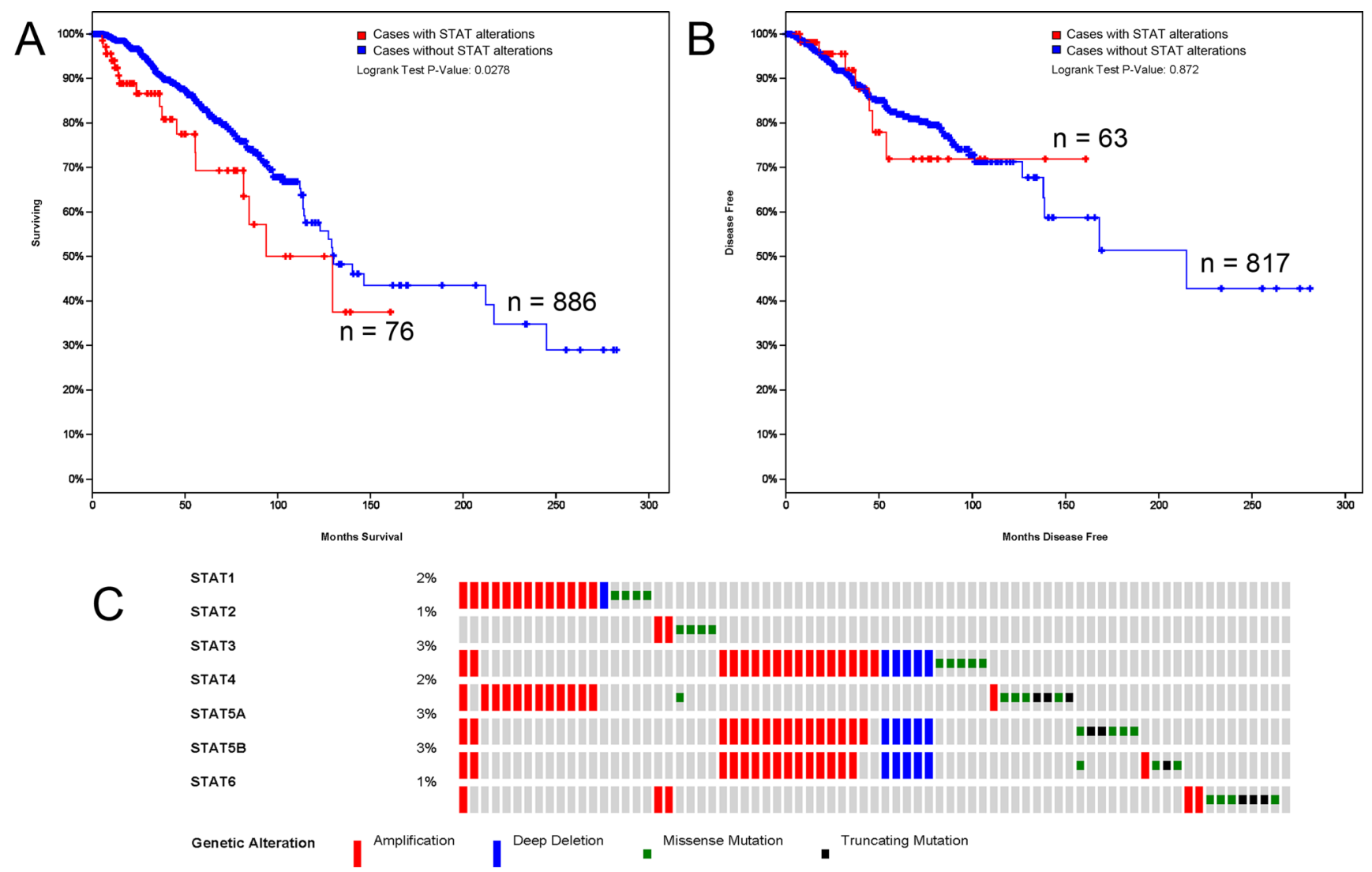

Figure 4: STAT genes expression and mutation analysis in breast invasive carcinoma (cBioPortal). (A) Kaplan-Meier plots comparing OS in cases with/without STAT alterations. (B) Kaplan-Meier plots comparing DFS in cases with/without STAT alterations. (C) Oncoprint in cBioPortal represented the proportion and distribution of samples with alterations in STAT factors. The figure was cropped on the right to exclude samples without alterations. 
Constitutive STAT5 activation is also observed in the majority of leukemias and many solid tumors, encoding by Stat $5 a$ and Stat $5 b$ genes on human chromosome 17 in a locus that also contains the Stat3 gene [31]. STAT5A and STAT5B are closely related members with $96 \%$ conserved at the protein level, and the highest degree of divergence is found in the C-terminal transactivation domain. Not surprisingly, both of their expressions were found to be suppressed in BC patients, especially with higher SBR grade. Importantly, the BC patient with higher STAT5A or STAT5B expression showed better RFS, providing a potential prognostic biomarker for BC. Yamashita et al. demonstrated that STAT5 expression is a predictive factor for endocrine therapy response and a strong prognostic molecular marker in ER+ breast cancer, predicting $\mathrm{BC}$ patients who may benefit from endocrine therapy [32]. The hormone prolactin (PRL) recruited STAT5 to increase transcription and cell proliferation, through dissociating Histone $\mathrm{H} 1$ mediated by chromosomal protein HMGN2 [33], providing a novel mechanism of full STAT5 recruitment.

At present, the research of STAT6 is primarily described in human breast cell lines and expressed in MCF7, like STAT2/4 [34]. Although no significant difference was found between the STAT6 expression in $\mathrm{BC}$ and normal tissues, the BC patients with high STAT6 expression level was predicted to have better survival in this study. The expression of STAT was correlated with increased levels of histological differentiation (SBR). STAT6 is induced by and required for IL-4-mediated growth inhibition and induction of apoptosis in human breast cancer cells [34, 35], confirming its anti-tumor function in BC. Recently, STAT6-TP63 pathway was reported to be activated by IL12Ralpha2, suppressing breast cancer lung metastasis [36]. STAT6 was found to be a novel target of PVT1-derived miR-1207-5p, and miR-1207-5p promoted breast cancer cell growth by targeting STAT6, which in turn control CDKN1A and CDKN1B [37], confirming the tumor suppressing role of STAT6 in breast cancer.

Although the alterations occurred in STATs affected the OS in BC patients, the main contributor and underling mechanism is still unclear. Vaclavicek et al. investigated the polymorphisms in JAK2 and STAT3/5A/5B genes in a case-control study and manifested putative association of STAT polymorphisms with increased risk odds ratio [38]. Recently, Slattery et al. examined 12 genes in JAK/STAT/SOCS signaling pathway with breast cancer risk and mortality and found that STAT6 rs3024979 and TYK2 rs280519 altered breast cancer-specific mortality among all women [39]. So the exact mechanism of STAT alteration with shorter $\mathrm{OS}$ in $\mathrm{BC}$ patients needs more investigations.

In this study, we systemically analyzed the expression and prognostic value of STATs in breast carcinoma, providing better understanding of the heterogeneity and complexity in the molecular biology of BC. Our finding supports that STAT3 was the potential treated target for breast cancer therapy, whereas STAT5A/5B/6 were potential prognostic markers for better survival of $\mathrm{BC}$, providing more accurate prognosis.

\section{MATERIALS AND METHODS}

\section{Ethics statement}

This study was approved by the Academic Committee of Shantou University Medical College, and conducted according to the principles expressed in the Declaration of Helsinki. All the datasets were retrieved from the publishing literature, so it was confirmed that all written informed consent was obtained.

\section{ONCOMINE analysis}

ONCOMINE gene expression array datasets (www. oncomine.org), an online cancer microarray database [40], was used to analyze the transcription levels of STATs in different cancers. The mRNA expressions of STATs in clinical cancer specimens were compared with that in normal controls, using a Students' $t$-test to generate a $p$ value. The cut-off of $p$ value and fold change were defined as 0.01 and 2 , respectively.

\section{Breast cancer gene-expression miner $\mathrm{v} 4.0$}

Breast Cancer Gene-Expression Miner v4.0 (bcGenExMiner v4.0) consisted 36 annotated genomic datasets and three statistical mining functions [41, 42]. The expression module was added on 2016/03/29, comparing the expression of a target gene according to clinical criteria, such as hormonal receptors, nodal status, and so on. The prognostic module assessed the prognostic impact of candidate genes in human $\mathrm{BC}$ and provided potential prognostic markers for $\mathrm{BC}$. The correlation module computed the correlation between genes or identified clusters of correlated co-expressed genes located in the same chromosomal region.

\section{The kaplan-meier plotter}

The prognostic value of STATs mRNA expression was evaluated using an online database, Kaplan-Meier Plotter (www.kmplot.com) [43], which contained gene expression data and survival information of 4,142 clinical breast cancer patients [44]. To analyze the relapse free survival (RFS) of patients with BC, patient samples were split into two groups by median expression (high vs. low expression) and assessed by a Kaplan-Meier survival plot, with the hazard ratio (HR) with $95 \%$ confidence intervals (CI) and logrank $p$ value. Only the JetSet best probe set of STATs were chosen to obtain Kaplan-Meier plots in which the Number-at-risk is indicated below the main plot. 


\section{TCGA data and cBioPortal}

The Cancer Genome Atlas had both sequencing and pathological data on 30 different cancers [45]. The breast invasive carcinoma (TCGA, Provisional) dataset including data from 1105 cases with pathology reports was selected for further analyses of STATs using cBioPortal (www. cbioportal.org) [46, 47]. The genomic profiles included mutations, copy-number variance (CNV) from GISTIC, mRNA expression z-scores (RNA Seq V2 RSEM) and protein expression z-scores (RPPA). OS and DFS were calculated according to the cBioPortal's online instruction.

\section{Abbreviations}

BC: Breast Carcinoma; BCSC: Breast Cancer Stem Cells; CI: Confidence Intervals; CNV: Copy-Number Variance; CPT: Crytotanshinone; DFS: Disease-Free Survival; ER: Estrogen Receptor; HER2: Epidermal Growth Factor Receptor 2; HR: Hazard Ratio; OS: Overall Survival; PR: Progesterone Receptor; RFS: Relapse-Free Survival; SBR: Scarff Bloom \& Richardson grade; STAT: Signal Transducer and Activators of Transcription; TCGA: The Cancer Genome Atlas; TNBC: Triple-Negative Breast Cancer;

\section{Authors' contributions}

H.T.W. and J.L. conceived and designed the research. H.T.W., J.L., G.W.L., J.X.S and Y.T.H. acquired and analyzed the data. H.T.W., J.L. and G.W.L. interpreted the results. H.T.W., J.L. and J.X.S. prepared figures and tables. H.T.W. and J.L. drafted, edited and revised manuscript.

\section{ACKNOWLEDGMENTS AND FUNDING}

This work was supported by National Natural Science Foundation of China (No. 81501539), Natural Science Foundation of Guangdong Province, China (No. 2015A030310211 \& 2016A030312008), and Youth Innovative Talent Project of Universities in Guangdong Province (No. 2014KQNCX078) and Personnel Training Project from the Education Department of Guangdong Province (Jing Liu), and Technology Planning Project of Shantou, China ([2014] No. 62 of Shantou Technology, to Hua-Tao $\mathrm{Wu}$ ).

\section{CONFLICTS OF INTEREST}

Disclose any potential conflicts of interest.

\section{REFERENCES}

1. Schindler C, Shuai K, Prezioso VR, Darnell JE Jr. Interferondependent tyrosine phosphorylation of a latent cytoplasmic transcription factor. Science. 1992; 257:809-13.
2. Haricharan S, Li Y. STAT signaling in mammary gland differentiation, cell survival and tumorigenesis. Mol Cell Endocrinol. 2014; 382:560-9. doi: 10.1016/j. mce.2013.03.014.

3. Siegel RL, Miller KD, Jemal A. Cancer statistics, 2015. CA Cancer J Clin. 2015; 65:5-29. doi: 10.3322/caac.21254.

4. Onitilo AA, Engel JM, Greenlee RT, Mukesh BN. Breast cancer subtypes based on ER/PR and Her2 expression: comparison of clinicopathologic features and survival. Clin Med Res. 2009; 7:4-13. doi: 10.3121/cmr.2009.825.

5. Proietti C, Salatino M, Rosemblit C, Carnevale R, Pecci A, Kornblihtt AR, Molinolo AA, Frahm I, Charreau EH, Schillaci R, Elizalde PV. Progestins induce transcriptional activation of signal transducer and activator of transcription 3 (Stat3) via a Jak- and Src-dependent mechanism in breast cancer cells. Mol Cell Biol. 2005; 25:4826-40. doi: 10.1128/MCB.25.12.4826-4840.2005.

6. Clevenger CV. Roles and regulation of stat family transcription factors in human breast cancer. Am J Pathol. 2004; 165:1449-60. doi: 10.1016/S0002-9440(10)63403-7.

7. Marrero MB, Schieffer B, Paxton WG, Heerdt L, Berk BC, Delafontaine P, Bernstein KE. Direct stimulation of Jak/ STAT pathway by the angiotensin II AT1 receptor. Nature. 1995; 375:247-50. doi: 10.1038/375247a0.

8. Kabotyanski EB, Rosen JM. Signal transduction pathways regulated by prolactin and Src result in different conformations of activated Stat5b. J Biol Chem. 2003; 278:17218-27. doi: 10.1074/jbc.M301578200.

9. Fox EM, Bernaciak TM, Wen J, Weaver AM, Shupnik MA, Silva CM. Signal transducer and activator of transcription $5 \mathrm{~b}, \mathrm{c}-\mathrm{Src}$, and epidermal growth factor receptor signaling play integral roles in estrogen-stimulated proliferation of estrogen receptor-positive breast cancer cells. Mol Endocrinol. 2008; 22:1781-96. doi: 10.1210/me.2007-0419.

10. Muller P, Kuttenkeuler D, Gesellchen V, Zeidler MP, Boutros M. Identification of JAK/STAT signalling components by genome-wide RNA interference. Nature. 2005; 436:871-5. doi: 10.1038/nature03869.

11. Sealfon SC, Chu TT. RNA and DNA microarrays. Methods Mol Biol. 2011; 671:3-34. doi: 10.1007/978-1-59745-551-0_1.

12. Curtis C, Shah SP, Chin SF, Turashvili G, Rueda OM, Dunning MJ, Speed D, Lynch AG, Samarajiwa S, Yuan Y, Graf S, Ha G, Haffari G, et al. The genomic and transcriptomic architecture of 2,000 breast tumours reveals novel subgroups. Nature. 2012; 486:346-52. doi: 10.1038/ nature 10983.

13. Gluck S, Ross JS, Royce M, McKenna EF Jr, Perou CM, Avisar E, Wu L. TP53 genomics predict higher clinical and pathologic tumor response in operable early-stage breast cancer treated with docetaxel-capecitabine +/- trastuzumab. Breast Cancer Res Treat. 2012; 132:781-91. doi: 10.1007/ s10549-011-1412-7.

14. Richardson AL, Wang ZC, De Nicolo A, Lu X, Brown M, Miron A, Liao X, Iglehart JD, Livingston DM, Ganesan S. 
$\mathrm{X}$ chromosomal abnormalities in basal-like human breast cancer. Cancer Cell. 2006; 9:121-32. doi: 10.1016/j. ccr.2006.01.013.

15. Finak G, Bertos N, Pepin F, Sadekova S, Souleimanova M, Zhao H, Chen H, Omeroglu G, Meterissian S, Omeroglu A, Hallett M, Park M. Stromal gene expression predicts clinical outcome in breast cancer. Nat Med. 2008; 14:518-27. doi: $10.1038 / \mathrm{nm} 1764$.

16. Zhao H, Langerod A, Ji Y, Nowels KW, Nesland JM, Tibshirani R, Bukholm IK, Karesen R, Botstein D, Borresen-Dale AL, Jeffrey SS. Different gene expression patterns in invasive lobular and ductal carcinomas of the breast. Mol Biol Cell. 2004; 15:2523-36. doi: 10.1091/mbc. E03-11-0786.

17. Chan SR, Vermi W, Luo J, Lucini L, Rickert C, Fowler AM, Lonardi S, Arthur C, Young LJ, Levy DE, Welch MJ, Cardiff RD, Schreiber RD. STAT1-deficient mice spontaneously develop estrogen receptor alpha-positive luminal mammary carcinomas. Breast Cancer Res. 2012; 14: R16. doi: 10.1186/bcr3100.

18. Klover PJ, Muller WJ, Robinson GW, Pfeiffer RM, Yamaji D, Hennighausen L. Loss of STAT1 from mouse mammary epithelium results in an increased Neu-induced tumor burden. Neoplasia. 2010; 12:899-905.

19. Kaplan DH, Shankaran V, Dighe AS, Stockert E, Aguet M, Old LJ, Schreiber RD. Demonstration of an interferon gamma-dependent tumor surveillance system in immunocompetent mice. Proc Natl Acad Sci U S A. 1998; 95:7556-61.

20. Suyama K, Onishi H, Imaizumi A, Shinkai K, Umebayashi M, Kubo M, Mizuuchi Y, Oda Y, Tanaka M, Nakamura M, Katano M. CD24 suppresses malignant phenotype by downregulation of SHH transcription through STAT1 inhibition in breast cancer cells. Cancer Lett. 2016; 374:44-53. doi: 10.1016/j.canlet.2015.12.013.

21. Jeon M, You D, Bae SY, Kim SW, Nam SJ, Kim HH, Kim S, Lee JE. Dimerization of EGFR and HER2 induces breast cancer cell motility through STAT1-dependent ACTA2 induction. Oncotarget. 2016 jul 26. doi: 10.18632/ oncotarget.10843. [Epub ahead of print].

22. Magkou C, Giannopoulou I, Theohari I, Fytou A, Rafailidis P, Nomikos A, Papadimitriou C, Nakopoulou L. Prognostic significance of phosphorylated STAT-1 expression in premenopausal and postmenopausal patients with invasive breast cancer. Histopathology. 2012; 60:1125-32. doi: 10.1111/j.1365-2559.2011.04143.x.

23. Uluer ET, Aydemir I, Inan S, Ozbilgin K, Vatansever HS. Effects of 5-fluorouracil and gemcitabine on a breast cancer cell line (MCF-7) via the JAK/STAT pathway. Acta Histochem. 2012; 114:641-6. doi: 10.1016/j. acthis.2011.11.010

24. Ogony J, Choi HJ, Lui A, Cristofanilli M, Lewis-Wambi J. Interferon-induced transmembrane protein 1 (IFITM1) overexpression enhances the aggressive phenotype of SUM149 inflammatory breast cancer cells in a signal transducer and activator of transcription 2 (STAT2)dependent manner. Breast Cancer Res. 2016; 18: 25. doi: 10.1186/s13058-016-0683-7.

25. Wu P, Wu D, Zhao L, Huang L, Shen G, Huang J, Chai Y. Prognostic role of STAT3 in solid tumors: a systematic review and meta-analysis. Oncotarget. 2016; 7:19863-83. doi: 10.18632/oncotarget.7887.

26. Bromberg JF, Wrzeszczynska MH, Devgan G, Zhao Y, Pestell RG, Albanese C, Darnell JE Jr. Stat3 as an oncogene. Cell. 1999; 98:295-303.

27. Jones LM, Broz ML, Ranger JJ, Ozcelik J, Ahn R, Zuo D, Ursini-Siegel J, Hallett MT, Krummel M, Muller WJ. STAT3 Establishes an Immunosuppressive Microenvironment during the Early Stages of Breast Carcinogenesis to Promote Tumor Growth and Metastasis. Cancer Res. 2016; 76:1416-28. doi: 10.1158/0008-5472. CAN-15-2770.

28. Zhang Z, Wang A, Li H, Zhi H, Lu F. STAT3-dependent TXNDC17 expression mediates Taxol resistance through inducing autophagy in human colorectal cancer cells. Gene. 2016; 584:75-82. doi: 10.1016/j.gene.2016.03.012.

29. Bui QT, Im JH, Jeong SB, Kim YM, Lim SC, Kim B, Kang KW. Essential role of Notch4/STAT3 signaling in epithelial-mesenchymal transition of tamoxifen-resistant human breast cancer. Cancer Lett. 2017; 390:115-25. doi: 10.1016/j.canlet.2017.01.014.

30. Zhou J, Xu XZ, Hu YR, Hu AR, Zhu CL, Gao GS. Cryptotanshinone induces inhibition of breast tumor growth by cytotoxic CD4+ T cells through the JAK2/STAT4/ perforin pathway. Asian Pac J Cancer Prev. 2014; 15:2439-45.

31. Azam M, Erdjument-Bromage H, Kreider BL, Xia M, Quelle F, Basu R, Saris C, Tempst P, Ihle JN, Schindler C. Interleukin-3 signals through multiple isoforms of Stat5. EMBO J. 1995; 14:1402-11.

32. Yamashita H, Nishio M, Ando Y, Zhang Z, Hamaguchi M, Mita K, Kobayashi S, Fujii Y, Iwase H. Stat5 expression predicts response to endocrine therapy and improves survival in estrogen receptor-positive breast cancer. Endocr Relat Cancer. 2006; 13:885-93. doi: 10.1677/erc.1.01095.

33. Schauwecker SM, Kim JJ, Licht JD, Clevenger CV. Histone H1 and Chromosomal Protein HMGN2 Regulate Prolactin-induced STAT5 Transcription Factor Recruitment and Function in Breast Cancer Cells. J Biol Chem. 2017; 292:2237-54. doi: 10.1074/jbc.M116.764233.

34. Gooch JL, Christy B, Yee D. STAT6 mediates interleukin-4 growth inhibition in human breast cancer cells. Neoplasia. 2002; 4:324-31. doi: 10.1038/sj.neo.7900248.

35. Zhang WJ, Li BH, Yang XZ, Li PD, Yuan Q, Liu XH, $\mathrm{Xu}$ SB, Zhang Y, Yuan J, Gerhard GS, Masker KK, Dong C, Koltun WA, et al. IL-4-induced Stat6 activities affect apoptosis and gene expression in breast cancer cells. Cytokine. 2008; 42:39-47. doi: 10.1016/j.cyto.2008.01.016.

36. Papageorgis P, Ozturk S, Lambert AW, Neophytou CM, Tzatsos A, Wong CK, Thiagalingam S, Constantinou AI. Targeting IL13Ralpha2 activates STAT6-TP63 pathway to 
suppress breast cancer lung metastasis. Breast Cancer Res. 2015; 17: 98. doi: 10.1186/s13058-015-0607-y.

37. Yan C, Chen Y, Kong W, Fu L, Liu Y, Yao Q, Yuan Y. PVT1-derived miR-1207-5p promotes breast cancer cell growth by targeting STAT6. Cancer Sci. 2017. doi: 10.1111/ cas. 13212 .

38. Vaclavicek A, Bermejo JL, Schmutzler RK, Sutter C, Wappenschmidt B, Meindl A, Kiechle M, Arnold N, Weber BH, Niederacher D, Burwinkel B, Bartram CR, Hemminki K, et al. Polymorphisms in the Janus kinase $2(\mathrm{JAK})$ /signal transducer and activator of transcription (STAT) genes: putative association of the STAT gene region with familial breast cancer. Endocr Relat Cancer. 2007; 14:267-77. doi: 10.1677/ERC-06-0077.

39. Slattery ML, Lundgreen A, Hines LM, Torres-Mejia G, Wolff RK, Stern MC, John EM. Genetic variation in the JAK/STAT/SOCS signaling pathway influences breast cancer-specific mortality through interaction with cigarette smoking and use of aspirin/NSAIDs: the Breast Cancer Health Disparities Study. Breast Cancer Res Treat. 2014; 147:145-58. doi: 10.1007/s10549-014-3071-y.

40. Rhodes DR, Yu J, Shanker K, Deshpande N, Varambally R, Ghosh D, Barrette T, Pandey A, Chinnaiyan AM. ONCOMINE: a cancer microarray database and integrated data-mining platform. Neoplasia. 2004; 6:1-6.

41. Jezequel P, Campone M, Gouraud W, Guerin-Charbonnel C, Leux C, Ricolleau G, Campion L. bc-GenExMiner: an easy-to-use online platform for gene prognostic analyses in breast cancer. Breast Cancer Res Treat. 2012; 131:765-75. doi: 10.1007/s10549-011-1457-7.
42. Jezequel P, Frenel JS, Campion L, Guerin-Charbonnel C, Gouraud W, Ricolleau G, Campone M. bc-GenExMiner 3.0: new mining module computes breast cancer gene expression correlation analyses. Database (Oxford). 2013; 2013: bas060. doi: 10.1093/database/bas060.

43. Gyorffy B, Surowiak P, Budczies J, Lanczky A. Online survival analysis software to assess the prognostic value of biomarkers using transcriptomic data in non-small-cell lung cancer. PLoS One. 2013; 8: e82241. doi: 10.1371/journal. pone. 0082241 .

44. Gyorffy B, Lanczky A, Eklund AC, Denkert C, Budczies J, Li Q, Szallasi Z. An online survival analysis tool to rapidly assess the effect of 22,277 genes on breast cancer prognosis using microarray data of 1,809 patients. Breast Cancer Res Treat. 2010; 123:725-31. doi: 10.1007/s10549-009-0674-9.

45. Cancer Genome Atlas Network. Comprehensive molecular portraits of human breast tumours. Nature. 2012; 490:61-70. doi: 10.1038/nature11412.

46. Gao J, Aksoy BA, Dogrusoz U, Dresdner G, Gross B, Sumer SO, Sun Y, Jacobsen A, Sinha R, Larsson E, Cerami E, Sander C, Schultz N. Integrative analysis of complex cancer genomics and clinical profiles using the cBioPortal. Sci Signal. 2013; 6: pl1. doi: 10.1126/scisignal.2004088.

47. Cerami E, Gao J, Dogrusoz U, Gross BE, Sumer SO, Aksoy BA, Jacobsen A, Byrne CJ, Heuer ML, Larsson E, Antipin Y, Reva B, Goldberg AP, et al. The cBio cancer genomics portal: an open platform for exploring multidimensional cancer genomics data. Cancer Discov. 2012; 2:401-4. doi: 10.1158/2159-8290.CD-12-0095. 